\title{
Spoken word recognition with gender-marked context
}

\author{
Elsa Spinelli, Fanny Meunier, and Alix Seigneuric \\ Laboratoire de Psychologie et NeuroCognition, Université Pierre Mendès \\ France, Grenoble, France / Laboratoire Dynamique du Langage, Lyon, \\ France / Université de Bourgogne, Dijon, France
}

\begin{abstract}
In a cross-modal (auditory-visual) fragment priming study in French, we tested the hypothesis that gender information given by a gender-marked article (e.g. $u n_{\text {masculine }}$ or $u n e_{\text {feminine }}$ ) is used early in the recognition of the following word to discard gender-incongruent competitors. In four experiments, we compared lexical decision performances on targets primed by phonological information only (e.g. /kRa/-CRAPAUD /kRapo/; /to/-TOAD) or by phonological plus gender information given by a gender-marked article (e.g. $u n_{\text {masculine }} / \mathrm{kra}$-CRAPAUD; a /to/-TOAD). In all experiments, we found a phonological priming effect that was not modulated by the presence of gender context, whether gender-marked articles were congruent (Experiments 1, 2, and 3) or incongruent (Experiment 4) with the target gender. Moreover, phonological facilitation was not modulated by the presence of gender context, whether gender-marked articles allowed exclusion of less frequent competitors (Experiment 1) or more frequent ones (Experiments 2 and 3). We concluded that gender information extracted from a preceding gender-marked determiner is not used early in the process of spoken word recognition and that it may be used in a later selection process.
\end{abstract}

Keywords: spoken word recognition, gender, priming

In languages with grammatical gender, the form of certain items like determiners and adjectives is dependent on grammatical or semantic properties of other items in the utterance (Corbett, 1991). In French, a language with two genders, each noun is either feminine or masculine. Determiners obey a gender agreement rule requiring an indefinite article preceding a masculine noun to be masculine (e.g. un $/ \tilde{\varepsilon} /)$, and an article preceding a feminine noun to be feminine (e.g. une /yn/). Since articles always precede nouns in French, the 
presence of the gender information associated with them could aid listeners by providing specific cues for decoding what they hear.

A number of studies have indeed shown effects of gender on word recognition. Grosjean, Dommergues, Cornu, Guillelmon, and Besson (1994) compared lexical decision times to nouns preceded by adjectives that were either auditorily unmarked for gender or preceded by a gender-marked determiner plus the same adjective (e.g., jolie table /zolitabl/ 'nice table' vs. une $e_{\text {fem }}$ jolie table /ynzolitabl/ 'a nice table'). Faster responses were found for the gender-marked condition, a result that was interpreted as indicating that gender marking on the article serves as a cue to the recognition of the noun. Recently, Bölte and Connine (2004) showed faster lexical decision times to targets preceded by gender-marked articles (either feminine, masculine or neutral in German) compared with targets preceded by a noise-masked article. Bates, Devescovi, Hernandez, and Pizzamiglio (1996) also showed gender priming (see also Bates, Devescovi, Pizzamiglio, D’Amico, \& Hernandez, 1995). They found that subjects were slower in shadowing noun targets preceded by gender-incongruent primes than those preceded by primes that were unmarked for gender. In the same experiment, faster responses were found in the gender-congruent condition than in the unmarked condition.

Dahan, Swingley, Tanenhaus, and Magnuson (2000) conducted an eyetracking study in French to assess the impact of gender on lexical access. In their experiments, participants were instructed auditorily to mouse-click on pictures of objects displayed on a computer screen. The probability of a subject fixating on a given picture was taken to indicate the activation of the lexical representation of the picture's name. When participants heard instruction sentences that did not include gender information - e.g., "cliquez sur les...", 'click on the..., where les is plural but not marked for gender - the probability of fixation was higher for pictures with names that shared the same initial phonemes as the target (the "cohort" effect) than for pictures with unrelated names. For example, if the instruction was "cliquez sur les boutons" (/butว̃/, 'buttons') participants would look more toward a picture of a bottle (bouteille /butcj/) than toward a picture of a $\operatorname{dog}\left(\right.$ chien $\left./ \int j \tilde{\varepsilon} /\right)$. This result was interpreted to mean that a cohort of candidates defined by their initial phonemes is activated by the speech signal (Allopenna, Magnuson, \& Tanenhaus, 1998). When a gendermarked article preceded the target noun - e.g., "cliquez sur le bouton", 'click on the button, where $l e$ is marked for masculine gender - the grammatically feminine members of the phonological cohort received no more fixations than the unrelated competitors. For the authors, this suggests that a gender-marked article preceding a noun can influence lexical activation. 
Spinelli and Alario (2002) examined whether gender information could constrain the activation of fully ambiguous words: homophones with two dif-

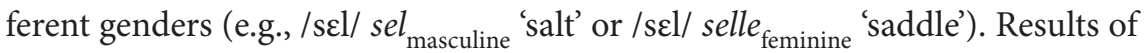
a cross-modal (auditory-visual) semantic priming study showed that when homophones were presented in isolation, facilitation was found for targets related to both the masculine (e.g., poivre, 'pepper') and the feminine (e.g., cheval, 'horse') meanings of the homophones. However, when homophones were presented with a gender-marked definite article (e.g., /lasel/ la selle 'the saddle'), facilitation was found only for targets related to the meaning matching the gender information given by the article (e.g., cheval 'horse'). No facilitation was found for targets related to the meaning mismatching the gender information (e.g., poivre 'pepper').

All these studies provide evidence of an influence of a gender-marked context on the activation of lexical candidates. However, it is unclear how gender context is used during the recognition of the following word. It could be that activation of lexical candidates is driven by the acoustic input only and that gender information is used later in the recognition process. Hence, a cohort of potential candidates would compete for recognition irrespective of their gender, and gender context would act later in the recognition process to select the appropriate candidate. For example, given the acoustic input, $u n_{\text {masc }} b o u \ldots$ /Ẽbu.../ in French, the competition would take place with all masculine and feminine words beginning with $/ \mathrm{bu} /$, the gender information extracted from a determiner (e.g., un) would then be used to give an extra boost of activation to select the appropriate candidate.

Another account of gender effects would be that a context marked for grammatical gender influences the early processes of lexical access. The gender information extracted from a determiner (e.g., feminine from la /la/ 'the' or une /yn/ 'one' in French) could then be used to discard candidates mismatched in gender (e.g. masculine candidates). A mechanism of this type would work in an all-or-none fashion: when a feminine determiner is processed, only feminine words compete for recognition. That is to say, the cohort of phonologically related candidates considered for selection would be restricted to those that have a gender matching the context. In German, Bölte and Connine (2004) carried out a corpus analysis order to assess whether the use of gender information could narrow down the number of lexical hypotheses during lexical access. It appears that gender information did indeed reduce the lexical search space as well as the amount of input needed to uniquely identify a word, at least in German. 
In the present study, we tested the hypothesis that gender information is used early in the process of lexical access to discard gender incongruent candidates from the competition process. Hence, given the acoustic input, $u n_{\text {masc }}$ bou / $\tilde{\varepsilon} \mathrm{bu} /$ in French, the competition will take place only among masculine words beginning with /bu/. Conversely, given the acoustic input, $u n e_{\text {fem }} b o u$ /ynbu/, the competition will take place only among feminine words beginning with /bu/. In the series of experiments presented here, we used a fragment priming paradigm in which the initial fragment of a target was presented as prime (e.g. /kRa/-CRAPAUD, /kRapo/) either with or without gender information (e.g. un masc $/ \mathrm{kRa} /$ or $/ \mathrm{kRa} /{ }^{1}$ ). The fragment priming paradigm is known to tap into early phases of word recognition and has been used as evidence of automatic activation of all compatible lexical candidates (i.e. multiple activation, Zwitserlood, 1989). Hence, if a context marked for gender influences the early processes of lexical access and constrains lexical activation to gender-congruent candidates only, phonological fragment priming should be modulated by the presence of gender. Moreover, the effect of gender should be greater for candidates having more frequent competitors of the opposite gender than for candidates having no more frequent competitors of the opposite gender.

Therefore, we manipulated the position of the candidate word in the cohort given the frequency of masculine and the feminine candidates. For example, if the candidate word bouteille $e_{\text {fem }}$ (/butej/ 'bottle') is the most frequent word of the cohort of words beginning with /bu/, this candidate should weakly benefit from the exclusion of the masculine, less frequent competitors. On the other

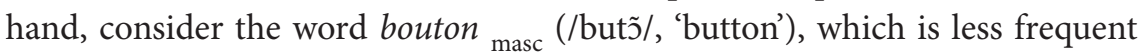
than bouteille, but is the most frequent masculine word in the cohort activated by /bu/. The activation of such a candidate (bouton), should be much greater

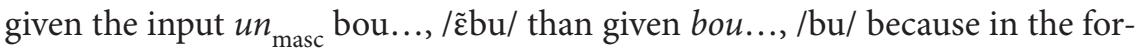
mer case, gender information allows exclusion of feminine candidate words (including the more frequent bouteille), hence leaving bouton as the most frequent of its cohort. Therefore, if a context marked for gender influences the early processes of lexical access by constraining lexical activation to gendercongruent candidates only, candidates with a more frequent competitor of the opposite gender should benefit more from gender context than candidates without more frequent competitors of the opposite gender.

Note that to test our hypothesis we rely on the fact that recognition of candidate words is slowed by the existence of higher frequency competitors compared to that of words without higher frequency competitors. There is indeed good evidence for this (Goldinger, Luce, and Pisoni, 1989; Radeau, Morais, \& Segui, 1995; Segui \& Grainger, 1990). Crucial to our purposes, in a cross modal 
fragment priming study, Marslen-Wilson (1990) showed that when fragments of targets were presented as primes, there was a larger facilitation effect for targets without higher frequency competitor (do-DOG) than for targets having more frequent competitors (ro-ROBE). Moreover, when the entire competitor was presented as a prime (dock-DOG; road-ROBE), inhibition was found for targets (ROBE) with a higher frequency competitor (road) but not for targets (DOG) with no higher frequency competitor.

In summary, if gender information given by a gender-marked context allows exclusion from the competition process of all related candidates with mismatching gender, (1) phonological priming should be modulated by the presence of preceding gender information and (2) gender information should benefit candidates with a more frequent competitor of the opposite gender more than those without. For example, un masc bou would benefit bouton more than $u_{n} e_{\text {fem }}$ bou would benefit bouteille, since bouton has a more frequent competitor of the opposite gender, i.e. the feminine word bouteille.

We conducted a series of cross-modal (auditory-visual) priming experiments in which the initial fragment of a target was presented as prime (e.g. /kRa/-CRAPAUD) either with or without gender information (e.g. un masc $/ \mathrm{kra} /$ or $/ \mathrm{kRa} /$ ). These conditions were compared to unrelated controls. In Experiment 1, targets had no more frequent competitor whereas in Experiment 2, targets had a more frequent competitor of the opposite gender. Hence in Experiment 1 , targets were the most frequent words of their cohort (e.g. CRAPAUD ${ }_{\text {masc }}$ for the cohort beginning with $/ \mathrm{kRa} /$ ) whereas in Experiment 2, targets were the

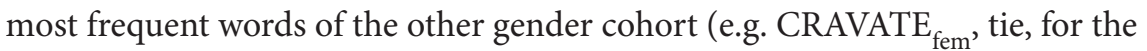
cohort of $u n e_{\text {fem }} / \mathrm{kRa} /$ ).

\section{Pretests}

Three pretests were carried out with several groups of first year psychology students (approximately fifty students in each group) in order to determine the most frequent word of a given cohort. Hence, "frequency" here refers to subjective frequency. The first group was presented to auditory syllables (e.g. (/kRa/ or $/ \mathrm{bu} / . .$.$) and had to write down the first word that came to mind beginning$ with this syllable (e.g. crapaud -toad- or bouteille -bottle). This first pretest allowed us to establish a list of the most (subjectively) frequent words of the cohort of a given syllable (/kRa/, /bu/, etc.). The second group was presented with the same auditory syllables preceded by an indefinite article marked for masculine gender (e.g. $u n_{\text {masc }} / \mathrm{kra} /$ or $u n_{\text {masc }} / \mathrm{bu} / \ldots$ ). The subjects had to write 
down the first masculine word that came to their mind beginning with this syllable (e.g. crapaud -toad- or bouton -button). This second pretest allowed us to establish a list of the most (subjectively) frequent masculine words of the cohort of a given syllable (/kra/ or /bu/...). Conversely, a third group was presented to the same auditory syllables preceded by an article marked for femi-

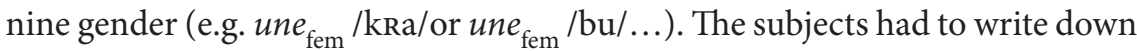
the first feminine word that came to their mind beginning with this syllable (e.g. cravate-tie- or bouteille -bottle). This last pretest allowed us to establish a list of the most (subjectively) frequent feminine words of the cohort of a given syllable (/kRa/, /bu/, etc.).

\section{Item selection for Experiment 1}

Targets of experiment 1 were the most frequent word in their cohort. Hence, for a masculine word to be selected for Experiment 1, it had to be the most frequent response in both the first and the second pretests. Moreover, it had to account for at least $17 \%{ }^{2}$ of the responses in the first pretest. Similarly, a feminine word was selected for the first experiment if (1) it was the most frequent response in the first and the third pretest and (2) if it was given as a response at least $17 \%$ of the time in the first pretest. Altogether, these three pretests allowed us to select 32 bi- or trisyllabic words that were the most frequent words of the cohort of a given syllable. They served as targets in Experiment 1.

\section{Item selection for Experiment 2}

Targets in Experiment 2 had one more frequent competitor of the opposite gender. Hence for a masculine word to be selected for Experiment 2, it had to be the most common response to a given item in the second pretest but not in the first one. Similarly, a feminine word was selected for Experiment 2 if it was the most common response in the third pretest but not in the first one. In other words, Experiment 2 targets were the most frequent of the cohort of the opposite gender. For example, if crapaud (toad ${ }_{\text {masc }}$, selected for Experiment 1 ) was the most frequent word of the /kRa/ cohort (determined as described above - it was the most frequently given response to both the auditory inputs /kRa/ and $u n_{\text {masc }} / \mathrm{kRa} /$ ), and cravate $_{\text {fem }}$ was the most frequent word of the feminine /kRa/ cohort of (since it was the most frequently responded item to the auditory input $u n e_{\mathrm{fem}} / \mathrm{kRa} /$ ). Cravate was then selected for Experiment 2. 
Table 1. Example of Materials Used as Primes and Targets in Experiments 1,2 and 4

\begin{tabular}{lllll}
\hline \multicolumn{2}{l}{ Priming conditions } & & \multicolumn{2}{c}{ TARGETS } \\
\hline EXP1 & Related & Without gender & With gender & \\
& Unrelated & {$[\mathrm{kra}]$} & {$[\tilde{\varepsilon} \mathrm{kra}]$ (congruent) } & CRAPAUD \\
\multirow{2}{*}{ EXP2 } & Related & {$[\mathrm{kra}]$} & {$[$ ynpli] } & {$[\mathrm{krapo}]$} \\
& Unrelated & {$[\mathrm{pli}]$} & {$[$ ynkra] (congruent) } & CRAVATE \\
\multirow{2}{*}{ EXP4 } & Related & {$[\mathrm{kra}]$} & {$[\tilde{\varepsilon}$ pli $]$} & {$[$ kravat $]$} \\
& Unrelated & {$[\mathrm{pli}]$} & {$[$ ynkra] (incongruent) } & CRAPAUD \\
& & & {$[\tilde{\varepsilon}$ pli $]$} & {$[\mathrm{krapo}]$} \\
\hline
\end{tabular}

\section{Experiment 1}

\section{Method}

\section{Participants}

Sixty students from the Pierre Mendès France University, Grenoble, participated in the experiment for course credit. All participants were native speakers of French, had normal or corrected vision and reported no hearing impairment.

\section{Stimuli and Design}

Words. Thirty-two target words (12 masculine words and 20 feminine words) that were the most frequent words of the cohort of a given syllable were selected, on the basis of the pretests described above. Four primes were chosen for each target. The first was a syllable corresponding to the first two or three phonemes of the target (e.g. /kRa/-CRAPAUD, beginning-overlap condition); the second corresponded to the syllable of the beginning-overlap condition preceded by an article marked for the target gender (e.g. / $\tilde{\varepsilon} k$ Ra/-CRAPAUD, beginningoverlap + gender condition ${ }^{3}$ ), the third was a syllable that was phonologically unrelated to the target (e.g. /pli/-CRAPAUD ${ }^{4}$, unrelated condition), and the fourth was a phonologically unrelated syllable preceded by a gender marked $\operatorname{article}^{5}$ (e.g. /ynpli/-CRAPAUD, unrelated + gender condition). It should be noted that syllables in the beginning-overlap conditions corresponded to the syllables that were used in the pretests. The experimental prime and target words are listed in the Appendix.

Pseudowords. Thirty-two bi- or triyllabic pseudoword targets were constructed for the lexical decision task. As for words, four primes were chosen for each target. The first corresponded to the first syllable of the target (e.g. /bRe/-BREGOT, beginning-overlap condition); the second corresponded the first syllable of the 
target preceded by an article (e.g. / $\tilde{b}$ be/-BREGOT, beginning-overlap + gender condition), the third was a syllable that was phonologically unrelated to the target (e.g. /pla/-BREGOT, unrelated condition), and the fourth was a phonologically unrelated syllable preceded by an article (e.g. /ynpla/-BREGOT, unrelated + gender condition). Examples of material used as primes and targets in all experiments are presented in Table 1.

In order to reduce the proportion of related items to $33 \%$, the experimental lists also included 64 filler prime/target pairs, half the targets being real words and the other half being pseudowords. The priming conditions for the filler targets were the unrelated condition (e.g. //o/ PIEUVRE 'octopus', /Re/-GUIBON (a pseudoword) and the unrelated + gender condition (e.g. une //o/ PIEUVRE, un /Re/-GUIBON) ${ }^{6}$.

\section{Procedure}

All items were recorded in a soundproof room by a female native speaker of French on a Mitsubish Diamond PTO $900 \mathrm{U}$ a PC at a sampling rate of $16 \mathrm{kHz}$. Participants were tested individually in a quiet room. The prime was presented auditorily at a comfortable sound level through Technics headphones. At the end of the auditory prime the target was visually displayed in lower case letters at the center of the computer screen and remained on the screen until the participant's response. Participants were informed that they would first hear an auditory sequence that could either be a syllable or a syllable preceded by a gender marked article, and that they would then see either a word or a pseudoword. They were required to perform a lexical decision task on the visual targets by pressing as accurately and as quickly as possible one of two response buttons. They were required to press the yes button with the forefinger of their preferred hand. The computer clock was triggered by the presentation of the target on the screen and stopped by the response. Stimuli were counterbalanced across four experimental lists so that each participant received all conditions (beginning-overlap, beginning-overlap + gender, unrelated and unrelated + gender) but saw each target only once. The order of prime/target pairs presentation was randomized. Response latencies and errors were collected. Each session lasted approximately twenty minutes.

\section{Results and Discussion}

The results are presented in Table 2. Incorrect responses (2.3\% of responses), and reaction times (RTs) longer than $1500 \mathrm{~ms}$ and those shorter than $200 \mathrm{~ms}$ $(0.2 \%)$ were removed. The data of one subject with a $30 \%$ error rate were also 
Table 2. Mean Reaction Times in Milliseconds (ms), Standard Deviation for Correct Responses to the Word Targets and Error Rates in the Four Priming Conditions of Experiment 1

\begin{tabular}{llll}
\hline & $\begin{array}{l}\text { Related (beginning } \\
\text { overlap) }\end{array}$ & Unrelated & Priming effect \\
\hline Without gender & $531 \mathrm{~ms}$ & $550 \mathrm{~ms}$ & $19 \mathrm{~ms}$ \\
& $(81)$ & $(90)$ & \\
& $1.5 \%$ & $3 \%$ & $20 \mathrm{~ms}$ \\
With congruent & $535 \mathrm{~ms}$ & $555 \mathrm{~ms}$ & \\
gender & $(84)$ & $(99)$ & \\
& $1.5 \%$ & $3.2 \%$ & \\
\hline
\end{tabular}

discarded from the analyses. Two-way analyses of variance with relatedness (related vs. unrelated) and presence of gender marking (without gender, with gender) were performed on the data. F values are reported by subjects $(F 1)$ and by items (F2) and all significance tests have associated $p$ levels of less than .05 .

Analyses of RTs revealed a main effect of relatedness, significant by subjects $(F 1(1,58)=10.2 ; p<.005)$, and by items $(F 2(1,31)=18.9 ; p<.001)$; target words were responded to more quickly when they were preceded by phonologically related primes than when preceded by unrelated primes. However, analyses of RTs revealed no main effect of the presence of gender marking (both $F$ s $<1$ ) and no interaction between these two factors (both $F_{s}<1$ ).

Analyses of error rates revealed a main effect of relatedness that was significant by subjects $(F 1(1,58)=5.38 ; p<.05 ; F 2(1,31)=2.7 ; p<.1)$. This result is in line with the RTs data: there were fewer errors for target words preceded by phonologically related primes than for target words preceded by unrelated primes. As with the RT data, analyses of errors revealed no main effect of the presence of gender and no interaction between these two factors (all $F_{s}<1$ ).

In this experiment, we found a phonological priming effect suggesting that presenting the beginning of a word (/kRa/ or $u n_{\text {masc }} / \mathrm{kRa} /$ ) activates the lexical representation of this word (CRAPAUD). This result is compatible with previous ones on fragment priming. In a study on Dutch, Zwitserlood (1989) found that both targets geld 'money' and boot 'ship' were facilitated when presented to participants during the /t/ of the semantically related primes Kapitaal 'capital' and Kapitein 'captain'. In a similar vein, Spinelli, Segui, and Radeau (2001) showed that presenting the beginning of a word (/ver/) activates the lexical representation of the word (vertigo).

However, no gender effect was found in the current experiment, CRA$P A U D$ was equally activated by phonological information only $(/ \mathrm{kra} /)$ and by 
phonological plus gender information ( $\left.u n_{\text {masc }} / \mathrm{kra} /\right)$. The fact that phonological priming effect is not modulated by the presence of gender suggests that gender context is not used early in the recognition of the following word. Note however that targets in this experiment were the most frequent candidates of the cohort. Therefore, it may be that no gender effect was found because gender information allowed the exclusion of less frequent competitors. On the contrary, a stronger gender effect is expected in Experiment 2 in which all targets have one more frequent competitor of the opposite gender. Gender information, in that case, should strongly aid processing of targets by excluding the higher frequency competitors.

\section{Experiment 2}

\section{Method}

\section{Participants}

Forty-one students from the Pierre Mendès France University, Grenoble, participated in the experiment for course credit. All participants were native speakers of French, had normal or corrected vision and reported no hearing impairment. None of them had participated in Experiment 1.

\section{Stimuli and Design}

Words. Thirty-two target words (12 feminine and 20 masculine words) were selected on the basis of the pretests described earlier. Each target word was the most frequent word of the gender constrained cohort of a given syllable, but not the most frequent of the general cohort (not constrained by gender). Hence, they had one more frequent competitor of the opposite gender. As for Experiment 1, four primes were chosen for each target corresponding to the beginning-overlap condition (e.g. /kRa/-CRAVATE), the beginning-overlap + gender condition (e.g. /ynkra/-CRAVATE), the unrelated condition (e.g. /pli/CRAVATE) and the unrelated + gender condition (e.g. / $\tilde{\varepsilon}$ pli/-CRAVATE). The experimental prime and target words are listed in the Appendix.

Pseudoword and filler pairs were the same as those in Experiment 1 except that the gender was swapped in order to keep the proportion of masculine/ feminine primes constant.

\section{Procedure}

The procedure paralleled that of Experiment 1. 


\section{Results and Discussion}

The results are presented in Table 3. The data of one subject with a $47 \%$ error rate were discarded from the analyses. Three items were discarded from the analyses for the same reason (57.5\% error rate for brouhaha, /bruaa/, $32.5 \%$ for tutu, /tyty/ and $40 \%$ for gourdin; /gurdẽ /) ${ }^{7}$. In addition, incorrect responses, RTs longer than $1500 \mathrm{~ms}$ and those shorter than $200 \mathrm{~ms}$ were removed, leading to the exclusion of $1.67 \%$ of the responses. Two-way analyses of variance with relatedness (related vs. unrelated) and presence of gender (without gender, with gender) were performed on the data.

Table 3. Mean Reaction Times in Milliseconds (ms), Standard Deviation for Correct Responses to the Word Targets and Error Rates in the Four Priming Conditions of Experiment 2

\begin{tabular}{llll}
\hline & $\begin{array}{l}\text { Related (beginning } \\
\text { overlap) }\end{array}$ & Unrelated & Priming effect \\
\hline Without gender & $535 \mathrm{~ms}$ & $545 \mathrm{~ms}$ & $10 \mathrm{~ms}$ \\
& $(81)$ & $(73)$ & \\
& $2.1 \%$ & $1.8 \%$ & $17 \mathrm{~ms}$ \\
With congruent & $536 \mathrm{~ms}$ & $553 \mathrm{~ms}$ & \\
gender & $(76)$ & $(92)$ & \\
& $1.1 \%$ & $1.7 \%$ & \\
\hline
\end{tabular}

Analyses of RTs revealed a main effect of relatedness, significant by subjects ( $F 1$ $(1,39)=4.7 ; p<.05 ; F 2(1,28)=3.3, p<.075)$. As in Experiment 1 , target words are responded to faster when they were preceded by phonologically related primes than when preceded by unrelated primes. Moreover, analyses of RTs revealed no main effect of the presence of gender marking (both $F_{s}<1$ ) and no interaction between these two factors (both $F_{s}<1$ ).

Analyses of errors revealed no effect of relatedness, no effect of the presence of gender and no interaction between these two factors (All $F_{S}<1$ ).

As in Experiment 1, we found a phonological priming effect suggesting that presenting the beginning of a word (/kra/ or $\left.\mathrm{une}_{\mathrm{fem}} / \mathrm{kra} /\right)$ activates the lexical representation of this word (CRAVATE). However, no gender effect was found, CRAVATE was equally activated by phonological information only (/ $\mathrm{kRa} /$ ) and by phonological plus gender information (une $\left.e_{\text {fem }} / \mathrm{kRa} /\right)$. Because all targets had one more frequent competitor of different gender, gender information was expected to help the processing of targets by excluding the higher frequency competitors.

As in Experiment 1, targets in the current experiment were presented at the acoustic offset of the primes (inter-stimulus interval (ISI) of $0 \mathrm{~ms}$ ). In the 
next experiment, we increased the duration of the ISI to $50 \mathrm{~ms}^{8}$ in order to give more processing time to the recognition system. The importance of processing time as opposed to sensorial information during word recognition has been highlighted by Zwitserlood and Schriefers (1995). In a cross-modal semantic study, they showed that a short fragment prime $(/ \mathrm{ka} /$, which is the beginning of Kapitein in Dutch) did not facilitate the subsequent processing of the target ADMIRAL (semantically related to Kapitein), whereas a longer fragment /kap/ significantly primed the target. Interestingly, the short fragment $/ \mathrm{ka} /$ plus some extra processing time did prime the target as efficiently as the long fragment. This study suggests that the information contained in the short fragment was sufficient to influence target's processing but some time was needed to affect the recognition system. In a similar vein, in the next experiment, we assessed whether extra processing time given to the system would reveal the influence of the gender information.

\section{Experiment 3}

\section{Method}

\section{Participants}

Thirty nine students from the Pierre Mendès France University, Grenoble, participated in the experiment for course credit. All participants were native speakers of French, had normal or corrected vision and reported no hearing impairment. None of them had participated in the previous experiments.

\section{Stimuli, Design and procedure}

Experiment 3 was the same as Experiment 2 except that the ISI was now $50 \mathrm{~ms}$.

\section{Results and Discussion}

The results are presented in Table 4. Incorrect responses, RTs longer than 1500 $\mathrm{ms}$ and those shorter than $200 \mathrm{~ms}$ were removed, leading to the exclusion of $2.1 \%$ of responses. As in the previous experiment, the same three items gave rise to a high percentage of errors and were discarded from the analyses (53.8\% error rate for brouhaha, /bruaa/, 28.2\% for tutu, /tyty/ and 25.6\% for gourdin; /gurdẽ/). Two-way analyses of variance with relatedness (related vs. unrelated) and presence of gender (without gender, with gender) were performed on the data. 
Table 4. Mean Reaction Times in Milliseconds (ms), Standard Deviation for Correct Responses to the Word Targets and Error Rates in the Four Priming Conditions of Experiment 3

\begin{tabular}{llll}
\hline & $\begin{array}{l}\text { Related (beginning } \\
\text { overlap) }\end{array}$ & Unrelated & Priming effect \\
\hline Without gender & $541 \mathrm{~ms}$ & $564 \mathrm{~ms}$ & $23 \mathrm{~ms}$ \\
& $(57)$ & $(74)$ & \\
& $0 \%$ & $3.6 \%$ & $25 \mathrm{~ms}$ \\
With congruent & $545 \mathrm{~ms}$ & $570 \mathrm{~ms}$ & \\
gender & $(73)$ & $(85)$ & \\
& $1.8 \%$ & $3 \%$ & \\
\hline
\end{tabular}

The results are similar to those of the previous experiment. Target words were responded to faster when they were preceded by phonologically related primes than when preceded by unrelated primes, $F 1(1,38)=11.1 ; p<.005)$; $F 2(1,28)=16.7 ; p<.005$. However, there is neither an effect of gender nor an interaction between the two factors (all $F_{s}<1$ ).

Analyses of error rates revealed a main effect of relatedness, significant by subjects $(F 1(1,38)=8.9 ; p<.005)$ and by items $(F 2(1,28)=7.3, p<.05)$. This result is in line with the RT data: there were fewer errors for target words preceded by phonologically related primes than for target words preceded by unrelated primes. Moreover, analyses of errors revealed no main effect of the presence of gender (both $F_{s}>1$ ) and no interaction between these two factors $(F 1(1,38)=1.4 ; \mathrm{ns}) ; F 2(1,28)=1.2 ; \mathrm{ns})$.

The pattern of results was the same whether the ISI was $50 \mathrm{~ms}$ (Experiment 2) or null (Experiment 3) which suggests that the absence of gender effect in the previous experiment was not due to insufficient processing time. Alternatively it could be that our design was not sensitive enough to show a gain in processing time for gender congruent candidates when incongruent competitors are eliminated. Hence, in our next attempt to find an early effect of gender, we directly examined the activation of gender incongruent competitors, by presenting prime-target pairs mismatched in gender (e.g. une $e_{\text {fem }}$ /kRa/-CRAPAUD masc $_{\text {- }}$. If gender-mismatched candidates are discarded early in the competition process, then we should find no phonological facilitation (or even inhibition) when incorrect gender information is available in addition to phonological information (e.g. une $_{\text {fem }} / \mathrm{kRa} /$-CRAPAUD $_{\text {masc }}$ ). In the next experiment, participants were presented with prime-target pairs that were mismatched in gender. 


\section{Experiment 4}

\section{Method}

\section{Participants}

Forty-four students from the Pierre Mendès France University, Grenoble, participated in the experiment for course credit. All participants were native speakers of French, had normal or corrected vision and reported no hearing impairment. None had participated in the previous experiments.

\section{Stimuli, Design and procedure}

In this experiment, the thirty-two target words were the same as those of Experiment 1 (i.e. the most frequent words of the cohort, e.g. CRAPAUD) and the primes were those used for Experiment 2. Therefore, that when gender information was available in the prime in addition to phonological information, the gender was not congruent with that of the target (e.g. une $e_{\mathrm{fem}} / \mathrm{kRa} /-$ CRAPAUD masc ).

\section{Results and Discussion}

The results are presented in Table 5. Incorrect responses and RTs longer than $1500 \mathrm{~ms}$ and those shorter than 200 were removed, excluding $2.9 \%$ of responses. Two-way analyses of variance with relatedness (related vs. unrelated) and presence of gender (without gender, with gender) were performed on the data.

Analyses of RTs revealed a main effect of relatedness, significant by subjects $(F 1(1,43)=16.2 ; p<.001)$, and by items $(F 2(1,31)=6 ; p<.05)$; target words were responded to more quickly when preceded by phonologically related primes than by unrelated primes. However, analyses of RTs revealed no

Table 5. Mean Reaction Times in Milliseconds (ms), Standard Deviation for Correct Responses to the Word Targets and Error Rates in the Four Priming Conditions of Experiment 4

\begin{tabular}{llll}
\hline & $\begin{array}{l}\text { Related (beginning } \\
\text { overlap) }\end{array}$ & Unrelated & Priming effect \\
\hline Without gender & $514 \mathrm{~ms}$ & $536 \mathrm{~ms}$ & $22 \mathrm{~ms}$ \\
& $(64)$ & $(78)$ & \\
& $1.7 \%$ & $4 \%$ & $16 \mathrm{~ms}$ \\
With incongruent & $514 \mathrm{~ms}$ & $530 \mathrm{~ms}$ & \\
gender & $(59)$ & $(54)$ & \\
& $3.4 \%$ & $2.6 \%$ & \\
\hline
\end{tabular}


main effect of the presence of gender and no interaction between these two factors (All Fs $<1$ ).

Analyses of error rates revealed no effect of relatedness $(F 1(1,43)=1.22$, ns; $F 2<1$ ), no effect of the presence of gender (Both $F s<1$ ), and no interaction between these two factors $(F 1(1,43)=3.06, p<.08 ; F 2(1,31)=3.52, p<.07)$.

As in all previous experiments, we found a priming effect suggesting that presenting the beginning of a word activates the lexical representation of this word, whatever gender is given in addition to phonological information. Targets were still facilitated when they were preceded by phonologically related primes with incongruent gender.

\section{General discussion}

In four experiments, we found a phonological priming effect suggesting that presenting the beginning of a word activates its lexical representation. This result is in line with previous studies showing fragment priming (Spinelli et al., 2001; Zwitserlood, 1989). However, this phonological facilitation was not modulated by the presence of gender information, whether this information was congruent with the target (Experiments 1, 2, and 3) or incongruent with the target (Experiment 4). Moreover, phonological facilitation was not modulated by the presence of gender information, whether this information allowed excluding less frequent competitors (Experiment 1) or more frequent ones (Experiments 2 and 3).

This study was designed to test whether gender information in the article affects lexical activation of the subsequent noun at an early stage. Four experiments, employing the cross-modal fragment priming technique (known to tap into early stages of lexical access) did not reveal any effect of gender, suggesting that it is not an effective contextual cue to delimiting the set of lexical candidates.

The fact that phonological facilitation was not modulated by the presence of gender contrasts with some results from the literature. Grosjean et al. (1994) found faster responses for the gender marked context condition (une jolie fille) compared to the unmarked condition (jolie fille), a result that was interpreted as an indication that gender marking on the article serves as a cue to the recognition of the noun. However, no indication of the timing of this process was given. Grammatical gender information could be available once words are recognized and affect lexical decision performance in a late process. The discrepancy with our results would then suggest that gender is not used 
in the early stages of activation. The same applies for results observed by Spinelli and Alario (2002), who found that the representation of the masculine candidate sel was not activated given the input/lasel/. Since that study used full priming (as opposed to fragment priming), those results suggest that by reaching the end of the auditory prime, gender incongruent competitors have been discarded from the competition process, but again no indication of the exact timing was given.

However, the results of Dahan et al. (2000) suggested an early influence of gender on lexical access. Using an eye tracking paradigm to follow the time course of activation of the competing candidates online, these authors showed that the feminine cohort-competitor bouteille is not activated during the auditory input /ləbutว̃/ while our results suggested that gender information has no early influence on the activation of competitors. This discrepancy might be explained, however, by the fact that the phonological cohort in Dahan et al's study was composed of only two competing candidates (since pictures of a bouton, 'button' and a bouteille, 'bottle' were displayed on a computer screen), whereas in our study, the cohort was open to all phonologically related candidates (all words beginning with $/ \mathrm{kra} /$, for example). One might then hypothesize that gender information might efficiently be used when it allows the listener to select the right candidate among a restricted choice. When the cohort is open to all related candidates, however, gender information might not be used early to constrain the activation process since it may not be efficient enough to rapidly narrow down the search space. Phonological information is surely the most efficient information to do so. Gender information could then take place during the selection phase following the initial activation phase constrained by phonological information only.

Other studies have suggested that gender effects do not tap into early processes of word recognition. Friederici and Jacobsen (1999) proposed that gender information does not serve in pre-selecting particular gender matching elements, but comes into play only at a post-lexical stage, during which gender agreement is checked (see also Colé \& Segui,1994, for a post access interpretation of the gender effect in the visual modality). In German, Bölte and Connine (2004) observed a gender facilitation effect in lexical decision task with faster lexical decision responses for words preceded by congruent articles. However, this effect was not replicated in a phoneme monitoring task, which is supposed to be very sensitive to degree of lexical activation. Moreover, there was no (or only weak) support for inhibitory influence of gender marking when gender was incongruent. Bölte and Connine suggested that the gender facilitation effect observed in the lexical decision task did not reflect an early influence 
of gender information. Rather, they argued, the effect could be explained by an increased familiarity of the target in the gender congruent condition: "the presence of a valid article increases the initial familiarity of a word, facilitating subsequent responses"(p. 1018). According to these authors, gender information is not utilized during early spoken word recognition since grammatical gender information is available once words are recognized. Considering this, the discrepancy between the Bölte and Connine gender facilitation effect and the absence of gender effect in the present study would come from the fact that the paradigm we used tapped into early stages of word recognition during which gender information might not be available.

A possible reconciliation of our present results with those showing a gender effect would be that early in the processing, all the potentially related competitors are activated, irrespective of their gender and of gender information that could be captured from the processing of a preceding determiner. Note that in the activation process, phonological information is surely the most efficient information cue to narrowing down the search space. Adding gender information seems to be of little help during the early process of activation, although gender information could be used later in processing. Hence the locus of gender effect might not be what we first hypothesized. It could be that a gender effect occurs during the selection phase of lexical access, following the initial activation phase. Although models of spoken word recognition differ in their view of the exact mechanisms underlying the selection process (Norris, 1994; McClelland \& Elman, 1986), they generally agree that spoken word recognition involves the activation of a set of lexical competitors and the selection of the target word from this activated set. Our data suggests that early lexical activation is only phonologically driven. The influence of gender information would then take place during the selection phase. More generally, this would suggest that the early stages of lexical access are independent of prior syntactic information.

\section{Author note}

This study has been supported by an "ACI Jeune Chercheur 2002 du Ministère de l'éducation nationale, de l'enseignement supérieur et de la recherche» and by the «Emergence 2002» program of Rhône-Alpes. We thank Gonia Jarema, Gary Libben and two anonymous reviewers for valuable comments on previous version of this manuscript. We also thank Pauline Welby for critical reading. 


\section{Notes}

1. Primes were presented auditorily and targets were presented visually.

2. The fact that selected targets were the most given item but nevertheless reached only $17 \%$ of the total responses reflects the productivity of the syllables that could give rise to many different lexical items.

3. We chose to prime noun targets with the indefinite articles un and une (as in Grosjean et al., 1994) instead of the definite articles le and la (as in Dahan et al. 2000; Spinelli \& Alario, 2002). Although the frequency of use of le/la is higher (on average 20973 occurrences per million, frequency given by "lexique 3" (New, Pallier, Ferrand, \& Matos, 2005) than that of un/une (on average 11573 occurrences per million), our choice was motivated by the fact that in French, the vowel of the definite article le or $l a$ is elided before vowel-initial words (e.g. l'artichaut, the unmarked 'artichoke'); with the exception of those words beginning with so-called aspirated vowels. It follows that the elided articles are no longer gender marked. We preferred the use of $u n$ and une which do not undergo any phonological change and are always gender marked. Moreover, Monnery (2001) showed a gender incongruency effect in a lexical decision task with consonant-initial targets that was stronger with indefinite articles as primes than with definite articles as primes.

4. In French, syllables often form words (e.g. pli, 'fold'). It could be argued that priming effect could be influenced by the lexical status of the prime. Spinelli et al. (2001) showed that it is not the case. They showed similar priming effects on targets with word and pseudowords syllable primes, that is, no effect of lexicality of the prime in such beginning overlap priming conditions.

5. In the unrelated + gender condition, the gender mark was systematically incongruent with the target. The reason for this was to avoid gender priming by the sole article.

6. Overall in the experiment, $54,7 \%$ of the target words were feminine and $45.3 \%$ were masculine. Fifty percent of prime syllables were preceded by masculine articles and $50 \%$ were preceded by feminine articles.

7. These items were nevertheless responded to as the most frequent ones given the auditory

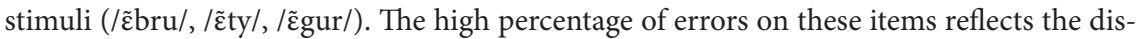
crepancy between off-line and on-line measures of lexical retrieval procedures.

8. We cannot ensure that $50 \mathrm{~ms}$ is enough to allow the processing of gender. However, increasing the ISI more than $50 \mathrm{~ms}$ in the phonological priming paradigm could lead to expectancy strategies (see Goldinger, Luce \& Pisoni, 1989; Hamburger \& Slowiaczek, 1996). Hence we chose not to use an ISI of more than $50 \mathrm{~ms}$. 


\section{References}

Allopenna, P.D., Magnuson, J.S., \& Tanenhaus, M.K. (1998). Tracking the time course of spoken word recognition using eye movements: Evidence for continuous mapping models. Journal of Memory and Language, 38, 419-439.

Bates, E., Devescovi, A., Pizzamiglio, L., D’Amico, S., \& Hernandez, A. (1995). Gender and lexical access in Italian. Perception \& Psychophysics, 57, 847-862.

Bates, E., Devescovi, A., Hernandez, A. \& Pizzamiglio, L. (1996). Gender priming in Italian. Perception \& Psychophysics, 58, 992-1004.

Bölte, J. \& Connine, C. M. (2004). Grammatical gender in spoken word recognition in German. Perception \& Psychophysics, 66, 1018-1032.

Colé P. \& Segui J. (1994).Grammatical incongruency and vocabulary types, Memory and Cognition, 22, 387-394.

Corbett, G. (1991). Gender. Cambridge University Press.

Dahan, D., Swingley, D., Tanenhaus, M. \& Magnuson, J. S. (2000). Linguistic gender and spoken-word recognition in French. Journal of Memory and Language, 42, 465-480.

Friederici, A.D. \& Jacobsen, T. (1999). Processing grammatical gender during language comprehension. Journal of Psycholinguistic Research, 28, 467-484.

Goldinger, S. D., Luce, P. A., Pisoni, D.B. (1989). Priming lexical neighbors of spoken words: effects of competition and inhibition. Journal of Memory and Language, 28, 501-518.

Grosjean, F., Dommergues, J-Y., Cornu, E., Guillelmon D. \& Besson, C. (1994). The gendermarking effect in spoken word recogntion. Perception \& Psychophysics, 56, 590-598.

Hamburger, M. B. \& Slowiaczek, L. M. (1996). Phonological priming reflects lexical competition. Psychonomic Bulletin \& Review, 3, 520-525.

Marslen-Wilson, W.D. (1990). Activation, competition, and frequency in lexical access. In G.Altmann (Ed.), Cognitive models of speech processing: Psycholinguistic and computational perspectives (pp.148-172). Cambridge, Ma: MIT Press.

McClelland, J. L. and Elman, J. L. (1986). The TRACE Model of Speech Perception. Cognitive Psychology, 18, 1-86.

Monnery, S. (2001). Calcul de l'attachement au sein du syntagme nominal. Unpublished dissertation. University of Burgundy, Dijon.

New B., Pallier C., Ferrand L., \& Matos R. (2001) Lexique: Une base de données lexicales du français contemporain sur internet. L'Année Psychologique, 101, 447-462.

Norris, D. (1994). Shortlist: A connectionist model of continuous speech recognition. Cognition, 52, 189-234.

Radeau, M., Morais, J., Segui, J. (1995) Phonological priming between monosyllabic spoken words, Journal of Experimental Psychology: Human Perception \& Performance,21 (6), 1297-1311.

Segui, J. Grainger, J. (1990) Priming word recognition with orthographic neighbors: Effects of relative prime-target frequency, Journal of Experimental Psychology: Human Perception \& Performance, 16, 65-76.

Spinelli, E. \&. Alario, F.X. (2002). Gender Context Effects on Homophone Words. Language and Cognitive Processes, 17, 457-469.

Spinelli, E. Segui, J., \& Radeau, M. (2001). Phonological Priming in Spoken Word recognition With Disyllabic Targets. Language and Cognitive Processes, 16, 367-392. 
Zwitserlood, P. (1989). The locus of the effects of sentential-semantic context in spokenword processing. Cognition, 32, 25-64.

Zwitserlood, P., \& Schriefers, H. (1995). Effects of sensory information and processing time in spoken word recognition. Language and Cognitive Processes, 10, 121-136.

\section{Author's address:}

Elsa Spinelli, Laboratoire de Psychologie et NeuroCognition, Université Pierre Mendes France, Bâtiment Sciences de l'Homme \& Mathématiques, BP 4738040 Grenoble Cedex 9, France. E-mail: elsa.spinelli@upmf-grenoble.fr. Phone: 0033 (0)4 768256 30. Fax: 0033 (0)476827834.

\section{Appendix}

Material Used as Primes and Targets in Experiments 1, 2, 3 and 4.

\begin{tabular}{|c|c|c|c|c|c|c|c|c|c|}
\hline \multirow{2}{*}{ TARGETS } & & & & \multicolumn{6}{|c|}{ PRIMES } \\
\hline & & & & \multicolumn{2}{|c|}{ Without gender } & \multicolumn{4}{|c|}{ With gender } \\
\hline $\begin{array}{l}\text { EXP1 } \\
\text { and } 4\end{array}$ & $\begin{array}{l}\text { Gen- } \\
\text { der }\end{array}$ & $\begin{array}{l}\text { EXP2 } \\
\text { and } 3\end{array}$ & $\begin{array}{l}\text { Gen- } \\
\text { der }\end{array}$ & $\begin{array}{l}\text { Begin- } \\
\text { ning } \\
\text { overlap }\end{array}$ & $\begin{array}{l}\text { Unre- } \\
\text { lated }\end{array}$ & \multicolumn{2}{|c|}{$\begin{array}{l}\text { Beginning } \\
\text { overlap } \\
(\exp 1)(\exp 2,3,4)\end{array}$} & \multicolumn{2}{|c|}{$\begin{array}{l}\text { Unrelated } \\
(\exp 1)(\exp 2,3,4)\end{array}$} \\
\hline $\begin{array}{l}\text { lardon } \\
\text { [lard }]\end{array}$ & $\mathrm{m}$ & $\begin{array}{l}\text { larme } \\
\text { [larm] }\end{array}$ & $\mathrm{f}$ & [lar] & [des] & 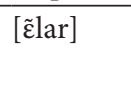 & [ynlar] & [yndes] & {$[\tilde{\varepsilon} \mathrm{d} \varepsilon s]$} \\
\hline $\begin{array}{l}\text { journée } \\
\text { [zurne] }\end{array}$ & $\mathrm{f}$ & $\begin{array}{l}\text { journal } \\
\text { [zurnal] }\end{array}$ & $\mathrm{m}$ & [3ur] & [pit] & [ynzur] & [ع̃zur] & [ $\tilde{\varepsilon}$ pit $]$ & [ynpit] \\
\hline $\begin{array}{l}\text { peinture } \\
\text { [pẽtyr] }\end{array}$ & $\mathrm{f}$ & $\begin{array}{l}\text { pinceau } \\
\text { [pẽso] }\end{array}$ & $\mathrm{m}$ & {$[\mathrm{p} \tilde{\varepsilon}]$} & [gy] & [ynp $\tilde{\varepsilon}]$ & [г̃ pyn] & 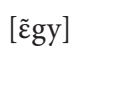 & [yngy] \\
\hline $\begin{array}{l}\text { grenouille } \\
\text { [grənuj] }\end{array}$ & $\mathrm{f}$ & $\begin{array}{l}\text { grenier } \\
\text { [grənje] }\end{array}$ & $\mathrm{m}$ & [grə] & [plã $]$ & [yngrə] & 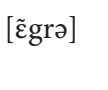 & [ع̃plã] & [ynplã] \\
\hline $\begin{array}{l}\text { pantalon } \\
\text { [pãtalõ] }\end{array}$ & $\mathrm{m}$ & $\begin{array}{l}\text { pendule } \\
\text { [pãdyl] }\end{array}$ & $\mathrm{f}$ & [pã] & [fy] & {$[\tilde{\varepsilon} \mathrm{p} \tilde{a}]$} & [ynpã] & [ynfy] & [ $\tilde{\varepsilon} f y]$ \\
\hline $\begin{array}{l}\text { fourmi } \\
\text { [furmi] }\end{array}$ & $\mathrm{f}$ & $\begin{array}{l}\text { fourneau } \\
\text { [furno] }\end{array}$ & $\mathrm{m}$ & [fur] & [pal] & [ynfur] & 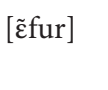 & [ẽpal] & [ynpal] \\
\hline $\begin{array}{l}\text { tulipe } \\
\text { [tylip] }\end{array}$ & $\mathrm{f}$ & tutu [tyty] & $\mathrm{m}$ & [ty] & [da] & [ynty] & 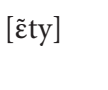 & {$[\tilde{\varepsilon} \mathrm{da}]$} & [ynda] \\
\hline $\begin{array}{l}\text { bateau } \\
\text { [bato] }\end{array}$ & $\mathrm{m}$ & $\begin{array}{l}\text { barque } \\
\text { [bark] }\end{array}$ & $f$ & {$[\mathrm{ba}]$} & {$[1 \tilde{\varepsilon}]$} & [ $\tilde{\varepsilon} \mathrm{ba}]$ & [ynba] & [ynlẽ ] & 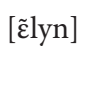 \\
\hline $\begin{array}{l}\text { gourde } \\
\text { [gurd] }\end{array}$ & $\mathrm{f}$ & $\begin{array}{l}\text { gourdin } \\
{[\operatorname{gurd} \tilde{\varepsilon}]}\end{array}$ & $\mathrm{m}$ & [gur] & [bas] & [yngur] & [ع̃gur] & 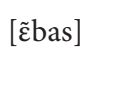 & [ynbas] \\
\hline $\begin{array}{l}\text { soulier } \\
\text { [sulje] }\end{array}$ & $\mathrm{m}$ & $\begin{array}{l}\text { soupe } \\
\text { [sup] }\end{array}$ & $\mathrm{f}$ & [su] & [mo] & {$[\tilde{\varepsilon} s u]$} & [ynsu] & [ynmo] & [थ̃mo] \\
\hline fille [fij] & $\mathrm{f}$ & filet [file] & $\mathrm{m}$ & {$[\mathrm{fi}]$} & [ly] & [ynfi] & {$[\tilde{\varepsilon} \mathrm{fi}]$} & [ع̃ly] & [ynly] \\
\hline
\end{tabular}




\begin{tabular}{|c|c|c|c|c|c|c|c|c|c|}
\hline $\begin{array}{l}\text { gorille } \\
\text { [gorij] }\end{array}$ & $\mathrm{m}$ & $\begin{array}{l}\text { gaufre } \\
\text { [gofr] }\end{array}$ & $\mathrm{f}$ & [go] & [pa] & [ع̃go] & [yngo] & [ynpa] & [ $\tilde{\varepsilon} \mathrm{pa}]$ \\
\hline $\begin{array}{l}\text { bronchite } \\
\text { [brõ } \text { it] }\end{array}$ & $\mathrm{f}$ & $\begin{array}{l}\text { bronze } \\
\text { [brõz] }\end{array}$ & $\mathrm{m}$ & [brõ] & [glã] & [ynbrõ] & 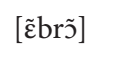 & 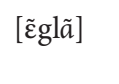 & [ynglã] \\
\hline $\begin{array}{l}\text { crapaud } \\
\text { [krapo] }\end{array}$ & $\mathrm{m}$ & $\begin{array}{l}\text { cravate } \\
\text { [kravat] }\end{array}$ & $\mathrm{f}$ & [kra] & [pli] & [ $\tilde{\varepsilon} \mathrm{kra}]$ & [ynkra] & [ynpli] & [ $\tilde{\varepsilon}$ pli] \\
\hline $\begin{array}{l}\text { maman } \\
\text { [mamã] }\end{array}$ & $\mathrm{f}$ & $\begin{array}{l}\text { matelot } \\
\text { [matlo] }\end{array}$ & $\mathrm{m}$ & [ma] & [to] & [ynma] & 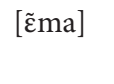 & [z̃ to] & [ynto] \\
\hline $\begin{array}{l}\text { voiture } \\
\text { [vwatyr] }\end{array}$ & $\mathrm{f}$ & $\begin{array}{l}\text { voilier } \\
\text { [vwalje] }\end{array}$ & $\mathrm{m}$ & [vwa] & [fว̃] & [ynvwa] & 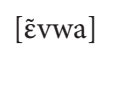 & {$[\tilde{\varepsilon} \tilde{\varepsilon} \tilde{3}]$} & [ynfõ] \\
\hline $\begin{array}{l}\text { brebis } \\
\text { [brəbi] }\end{array}$ & $\mathrm{f}$ & $\begin{array}{l}\text { breton } \\
\text { [brətว̃] }\end{array}$ & $\mathrm{m}$ & [brə] & [gla] & [ynbrə] & 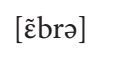 & [ẽgla] & [yngla] \\
\hline $\begin{array}{l}\text { lapin } \\
\text { [lap } \tilde{\varepsilon}]\end{array}$ & $\mathrm{m}$ & lame [lam & ]f & [la] & [mo] & 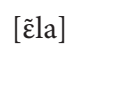 & [ynla] & [ynmo] & {$[\tilde{\varepsilon} \mathrm{mo}]$} \\
\hline $\begin{array}{l}\text { pratique } \\
\text { [pratik] }\end{array}$ & $\mathrm{f}$ & $\begin{array}{l}\text { praticien } \\
\text { [pratisjẽ }\end{array}$ & $\mathrm{m}$ & [pra] & [pli] & [ynpra] & [ẽpra] & [ẽpli] & [ynpli] \\
\hline table [tabl] & ]f & tapis [tapi] & $\mathrm{m}$ & {$[\mathrm{ta}]$} & [ly] & [ynta] & {$[\tilde{\varepsilon} t a]$} & 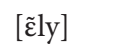 & [ynly] \\
\hline $\begin{array}{l}\text { cheveu } \\
\text { [/əvø] }\end{array}$ & $\mathrm{m}$ & $\begin{array}{l}\text { cheminée } \\
\text { [jəmine] }\end{array}$ & f & [ృ] & [bã] & {$\left[\tilde{\varepsilon} \int \partial\right]$} & [ynjə] & [ynbã] & 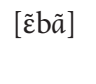 \\
\hline $\begin{array}{l}\text { brouette } \\
\text { [bruct] }\end{array}$ & $\mathrm{f}$ & $\begin{array}{l}\text { brouhaha } \\
\text { [bruaa] }\end{array}$ & $\mathrm{m}$ & [bru] & [fly] & [ynbru] & 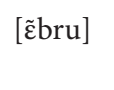 & 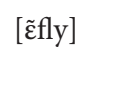 & [ynfly] \\
\hline $\begin{array}{l}\text { ruelle } \\
\text { [ryel] }\end{array}$ & $\mathrm{f}$ & $\begin{array}{l}\text { rhume } \\
\text { [rym] }\end{array}$ & $\mathrm{m}$ & [ry] & [pa] & [ynry] & 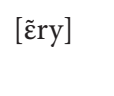 & 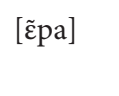 & [ynpa] \\
\hline $\begin{array}{l}\text { bonbon } \\
\text { [bõbõ] }\end{array}$ & $\mathrm{m}$ & $\begin{array}{l}\text { bombe } \\
\text { [bj̃b] }\end{array}$ & $\mathrm{f}$ & [bõ] & [fy] & 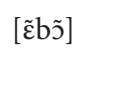 & [ynbz̃] & [ynfy] & {$[\tilde{\varepsilon} f y]$} \\
\hline 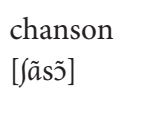 & $\mathrm{f}$ & $\begin{array}{l}\text { cham- } \\
\text { pignon } \\
\text { [sãpiñ̃] }\end{array}$ & $\mathrm{m}$ & {$\left[\int \tilde{a}\right]$} & {$[\mathrm{li}]$} & {$\left[\operatorname{yn} \int \tilde{a}\right]$} & $[\tilde{\varepsilon}) \tilde{a}]$ & [ $\tilde{\varepsilon} l i]$ & [ynli] \\
\hline $\begin{array}{l}\text { girafe } \\
\text { [3iraf] }\end{array}$ & $\mathrm{f}$ & gîte [3it] & $\mathrm{m}$ & [3i] & [pa] & [ynzi] & {$[\tilde{\varepsilon} 3 \mathrm{i}]$} & [г̃pa] & [ynpa] \\
\hline $\begin{array}{l}\text { coiffeur } \\
\text { [kwafər] }\end{array}$ & $\mathrm{m}$ & $\begin{array}{l}\text { coiffure } \\
\text { [kwafyr] }\end{array}$ & $\mathrm{f}$ & [kwa] & [bã] & 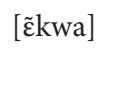 & $\begin{array}{l}\text { [ynk- } \\
\text { wa] }\end{array}$ & [ynbã] & {$[\tilde{\varepsilon} \mathrm{b} \tilde{a}]$} \\
\hline $\begin{array}{l}\text { garçon } \\
\text { [garss̃] }\end{array}$ & $\mathrm{m}$ & gare [gar] & $\mathrm{f}$ & [ga] & [mir] & [च̃ga] & [ynga] & [ynmir] & [ $\tilde{\varepsilon}$ mir $]$ \\
\hline $\begin{array}{l}\text { famille } \\
\text { [famij] }\end{array}$ & $\mathrm{f}$ & $\begin{array}{l}\text { fardeau } \\
\text { [fardo] }\end{array}$ & $\mathrm{m}$ & {$[\mathrm{fa}]$} & [gy] & [ynfa] & {$[\tilde{\varepsilon} \mathrm{fa}]$} & [ $\tilde{\varepsilon} g y]$ & [yngy] \\
\hline $\begin{array}{l}\text { bouteille } \\
\text { [butej] }\end{array}$ & $\mathrm{f}$ & $\begin{array}{l}\text { bouton } \\
\text { [butว̃] }\end{array}$ & $\mathrm{m}$ & {$[\mathrm{bu}]$} & {$[\mathrm{r} \tilde{a}]$} & [ynbu] & {$[\tilde{\varepsilon} \mathrm{bu}]$} & {$[\tilde{\varepsilon} r \tilde{a}]$} & [ynrã] \\
\hline $\begin{array}{l}\text { clôture } \\
\text { [klotyr] }\end{array}$ & $\mathrm{f}$ & $\begin{array}{l}\text { clochard } \\
\text { [klofar] }\end{array}$ & $\mathrm{m}$ & [klo] & [pri] & [ynklo] & 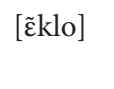 & 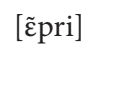 & [ynpri] \\
\hline $\begin{array}{l}\text { plateau } \\
\text { [plato] }\end{array}$ & $\mathrm{m}$ & $\begin{array}{l}\text { place } \\
\text { [plas] }\end{array}$ & $\mathrm{f}$ & [pla] & [kro] & 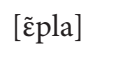 & [ynpla] & [ynkro] & 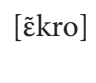 \\
\hline
\end{tabular}


